\title{
Revisão do Programa: Multimedia Methods in Molecular Biology; 2nd. Ed.
}

\author{
(Software Review: Multimedia Methods in Molecular Biology; 2nd. Ed.)
}

\author{
Autores:Andre Kimura Okamoto \\ Afiliação:Depto. de Físico-Química - IQ/UNICAMP \\ a_k_okamoto@mac.com
}

During this past two decades, multimedia methods have been frequently highlighted as an alternative teaching solution, thus they must be constantly evaluated and corrected in order to avoid a banal use of these tools. This software review evaluated the level of agreement between the authors/editors proposals and its actual relevance and ease o use. Future corrections are expected due to major flaws found in its use.

Multimedia Methods in Molecular Biology; 2nd. Ed.

Editado por: T. Patridge, P. Jones, D. Rickwood

Chapman and Hall, 2000

website: http://www.multimediamethods.com/

preço: GBP 295,00

\section{Aspectos Gerais}

A proposta do pacote é prover uma ambiente customizado de referência, com a possibilidade de adição de registros protegidos por senha. Os métodos de laboratório mais comuns já estão inclusos, e podem ser abertos por qualquer pessoa que tenha autorização para utilizar o pacote. Isso é feito através de um usuário administrador, que confere a cada usuário um nome para autenticação e uma senha, e controla o acesso aos registros adicionais inseridos pelos próprios usuários.

Portanto, vemos que este é um pacote cuja principal utilização deve ser o uso como referência. Dentro podemos encontrar elementos que abrigam os conceitos básicos dos bons aplicativos modernos - instalação rápida e facilidade de uso - e esses elementos estão bem direcionados para a solução de gerenciamento de descrição de metodologias utilizados comumente na maioria dos laboratórios de biologia molecular, provendo acesso às informações pertinentes de métodos conhecidos na área, e de armazenamento de métodos modificados ou inéditos, que podem ser salvos e acrescentados ao conjunto pré-existente no pacote.

O pacote pode incuir um CD-ROM para as plataformas Apple Macintosh, ou Intel/Windows, e um livreto que contém desde as instruções básicas de instalação até um guia para a inserção de seu próprio conjunto de protocolos, ressaltando mais uma vez esta característica deste programa, que o torna atrativo. Mas a interface de uso é bastante espartana, como pode ser observado logo na inicialização do programa. Mesmo com a capacidade de gerar gráficos a $1024 \times 768$ pixels por polegada de resolução em Milhões de Cores (Millions of Colours, equivalente ao "True Color" no sistema operacional Windows), a qualidade das figuras é a mesma daquela gerada em $640 \times 480$ pixels, portanto, alterar as configurações de seu computador não servirá em nada para incrementar a visualização da parte gráfica. Provavelmente, esse é o motivo pelo qual os requerimentos básicos para instalação são bastante modestos.

Um aspecto negativo é a alteração de configuração das teclas de atalho (ou "shortcuts") mais comuns. Usuários da plataforma Windows não devem pensar que isso seja realmente um problema (uma vez que parece não existir padrão ou lógica para isso na plataforma) entretanto muitos desses atalhos são bem conservados nos programas mais diversos para MacOS, mesmo em versões de idiomas diferentes, o que 
facilita bastante da criação de teclas de atalho (e faz juz ao uso). Portanto, deve-se estar atento a essas mudanças, que felizmente estão devidamente descritas no livreto que acompanha o pacote.

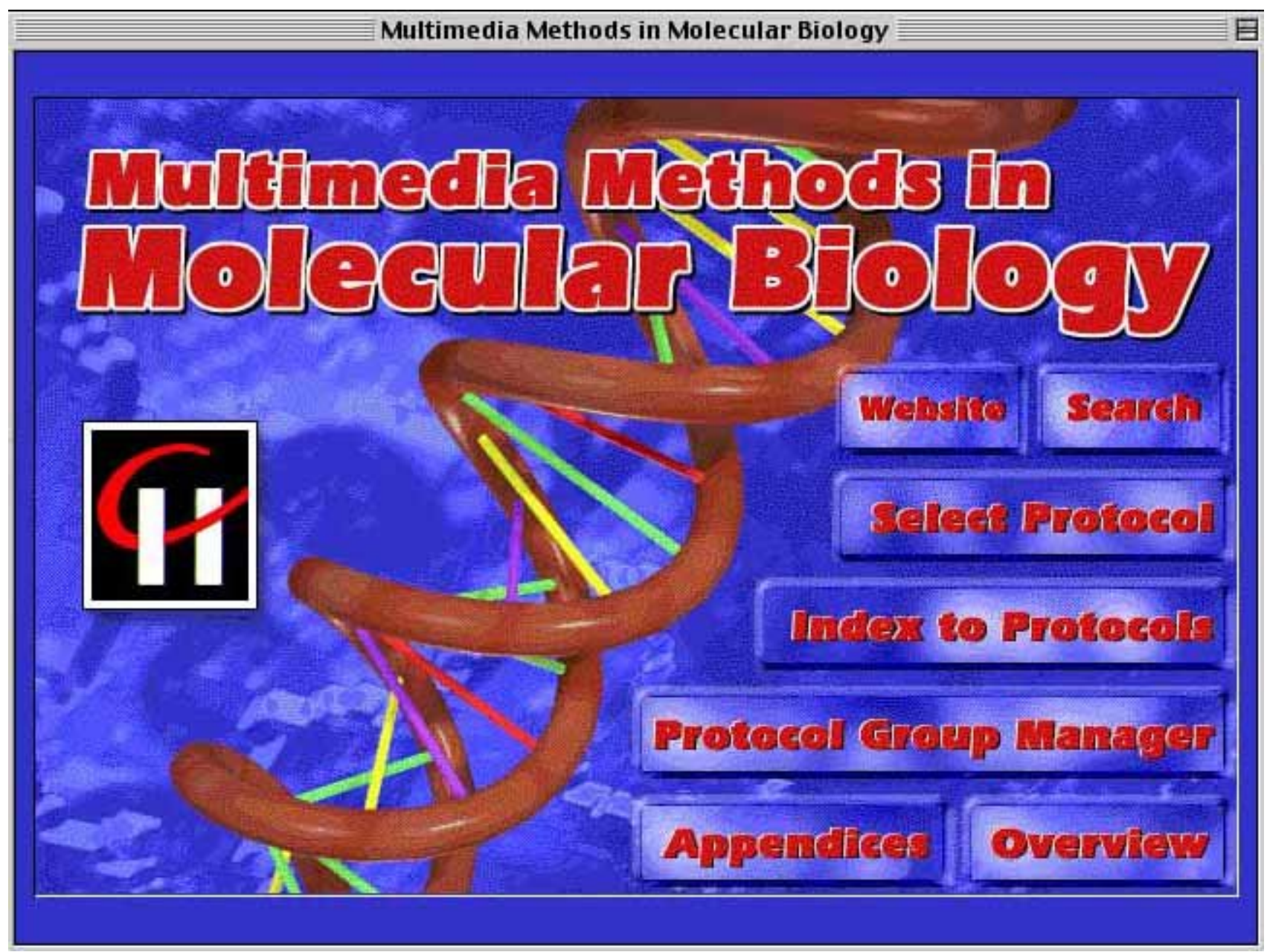

Fig.1.: A Tela Principal: após a autenticação do usuário, as mais diversas ferramentas são acessadas clicandose nos botões, que podem requerer acesso à Internet.

\section{O Poder Necessário:}

Necessidades Básicas:

Macintosh (configuração mínima):

Processador Motorola 68030, 15MB de memória RAM, 8MB de disco rígido (HD), MacOS 7.x, Quick Time, resolução gráfica de $640 \times 480$ pixels por polegada em 256 colours, unidade de CD-ROM de velocidade quádrupla.

Intel x86/Windows (configuração mínima):

Processador 80486 ou equivalente, 15MB de memória RAM, 8MB de HD, Microsoft (MS) Windows 3.x ou 9x ou NT, MS Video for Windows (fornecido no CD-ROM), resolução gráfica de 640x480 pixels por polegada em 256 cores, unidade de CD-ROM de velocidade quádrupla.

\section{Sistemas Usados nos testes:}

Macintosh:

Performa 6230CD, 64MB de RAM, 8,4GB de HD, MacOS 9.1, Quick Time 4.0, resolução gráfica de $832 \times 624$ 
PowerMac 7100AV/66, 54MB de RAM, 280MB de HD, MacOS 9.1, Quick Time 5.0.1, resolução gráfica de $1024 \times 768$ pixels por polegada em Milhões de Cores, 4xCD-ROM drive.

\section{As Duas Faces da Mesma Moeda:}

A instalação é bastante simples: após a inserção do CD-ROM no drive uma janela será aberta na área de trabalho. Com um duplo-clique no ícone do instalador todo o processo é inicializado. Você deve reiniciar o computador após a instalação; no entanto, é possível iniciar o programa, mesmo sem a reinicialização, que deve ser necessária provavelmente devido à instalação do QuickTime, no entanto, isso não é aconselhável, como observado nos testes. Também é necessário que o CD-ROM esteja inserido no drive pois o programa necessita carregar informações contidas no $C D$, e não se inicializará se isso não ocorrer.

Como mencionado anteriormente, este é um CD-ROM de referência, portanto o usuário tem acesso a muitas informações úteis à respeito dos procedimentos experimentais mais comuns no dia-a-dia de um laboratório de biologia molecular, incluindo informações detalhadas dos reagentes usados, riscos na manipulação desses reagentes, noções de segurança laboratorial, 'receitas' de preparo dos reagentes, e como conduzir o experimento em si. Filmes curtos no formato QuickTime e esquemas também estão disponíveis para alguns protocolos, mas, infelizmente parece que os editores preferiram manter a compatibilidade com sistemas computacionais antigos ao invés de desenvolver mais este tipo de material.

Quanto ao uso, basicamente, um usuário Mestre ("Master") é inicialmente configurado. Esse usuário controla todas as permissões e acessos às ferramentas do pacote: adiciona/remove usuários, administra grupos e atualiza o software quando necessário. As ferramentas do pacote não estão acessíveis ao usuário Mestre, portanto mesmo se você é o único usuário, você deve criar sua própria conta. Todos os usuários devem autenticar-se através de nome de usuário e senha, e ao final de cada sessão deve-se fechar o acesso, e fechar o aplicativo, se necessário.

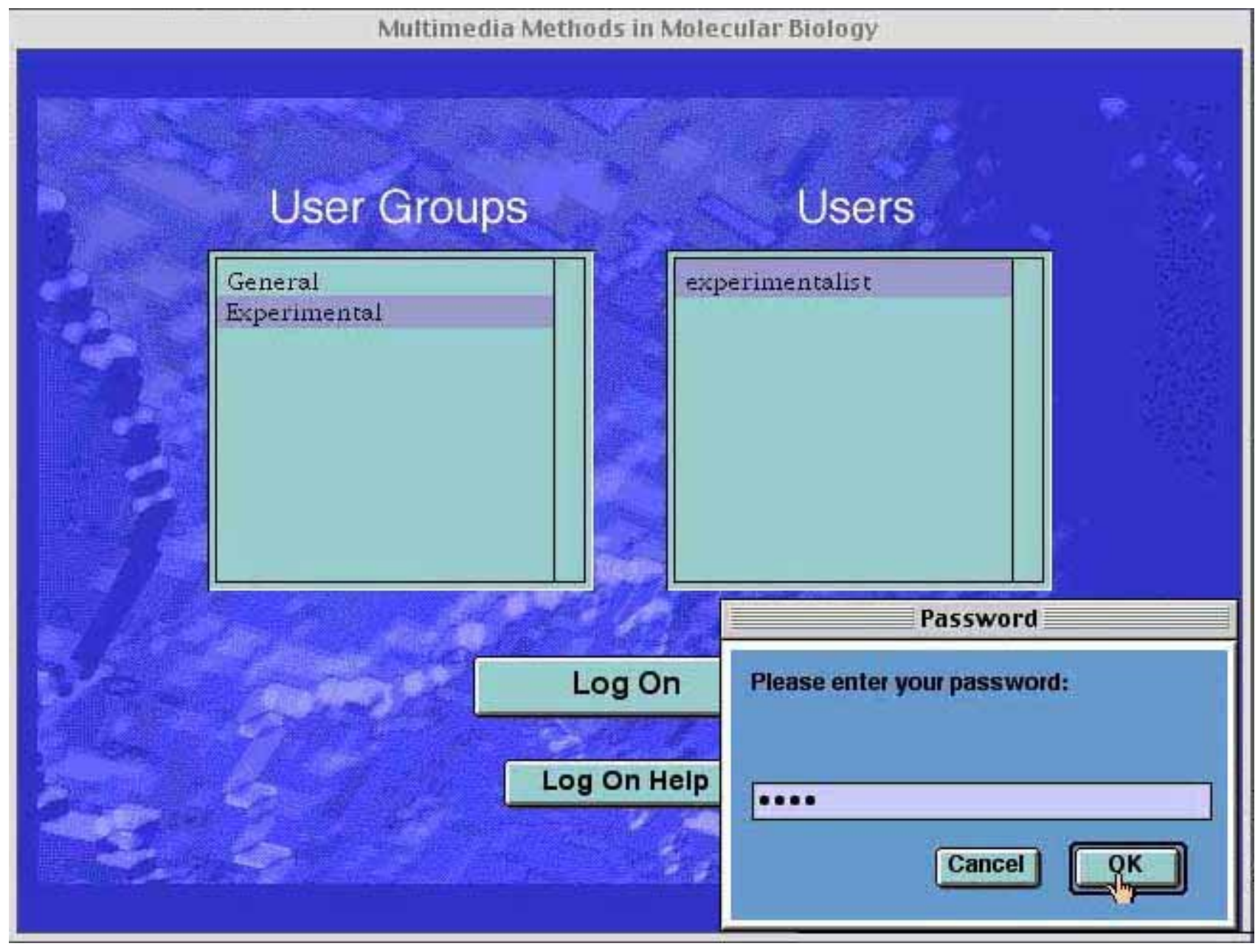


Fig.2.: Tela de autenticação ("logon"). O usuário Mestre ("Master") deve configurar previamente o acesso dos outros usuários.

Como o aplicativo permite a inserção e edição de protocolos novos, existem algumas 'precauções' a serem tomadas: estes novos protocolos, recém adicionados, devem ser mantidos à salvo dos 'espiões', requisito necessário deste mundo moderno cheio de novas paranóias, infelizmente. Daí a funcionalidade da existência de um administrador e de nomes de autenticação e senha para usuários. Mas reside aí também outra infelicidade, pois os arquivos podem ser lidos por outros aplicativos, portanto o usuário deve se preocupar bastante se adicionar suas informações confidenciais. O Simple Text, WordPad, ou qualquer outro processador de textos são capazes de reconhecer o formato dos arquivos deste pacote. Essa é uma falha que certamente precisa ser removida em versões futuras do pacote. Se essa falha não for corrigida, qual a necessidade de se criar grupos e usuários para manter o sigilo de informações, se isso não é barreira (tampouco proteção eficiente) contra o acesso indiscriminado das informações, as quais, no meu conceito (e, certamente de muitos outros), são muito mais importantes do que uma interface de usuário "bonitinha". Portanto, tenha isso em consideração antes de adquirir esta versão do pacote!

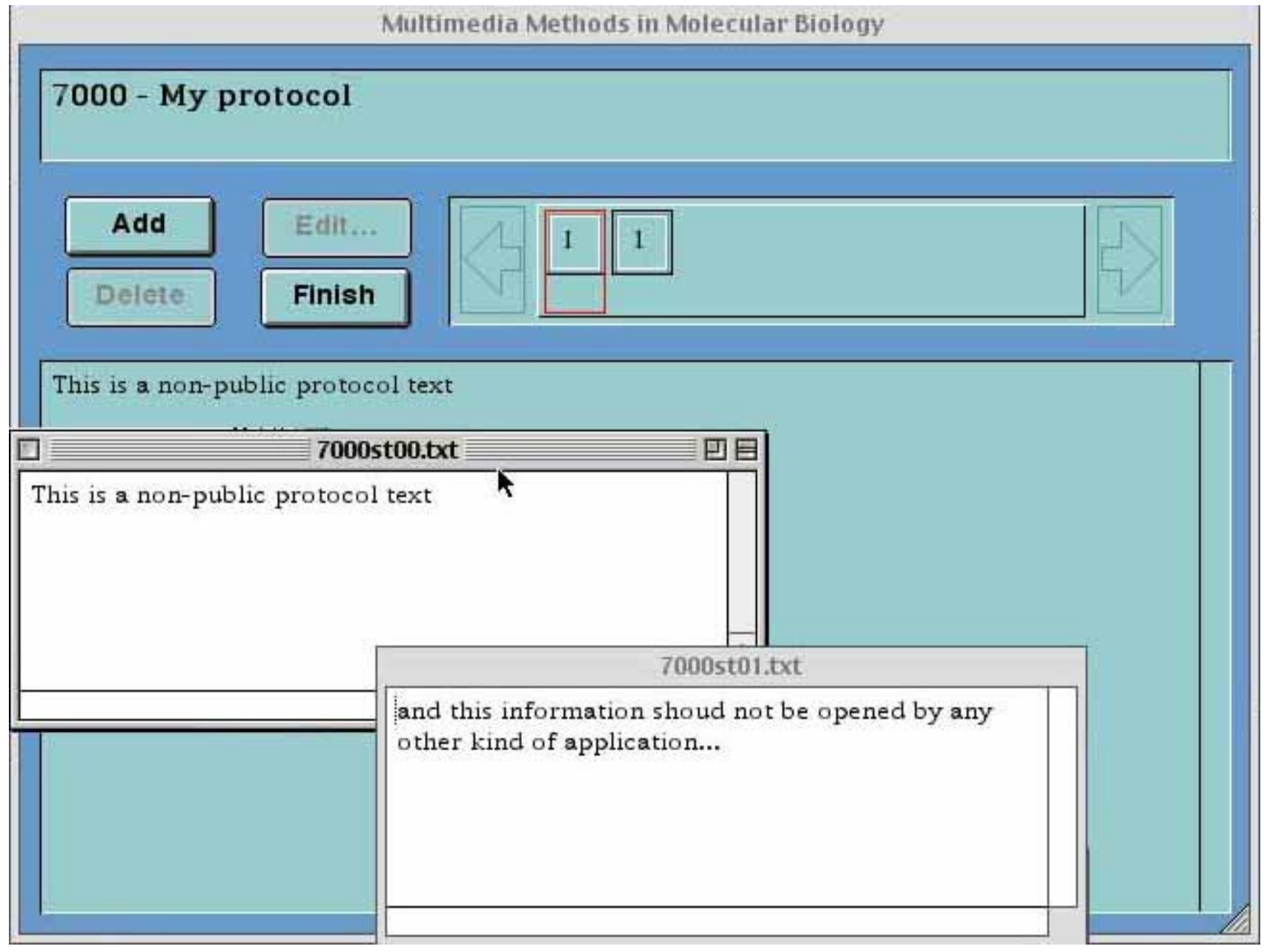

Fig.3a.: Este é o procedimento para a criação de um novo protocolo. 


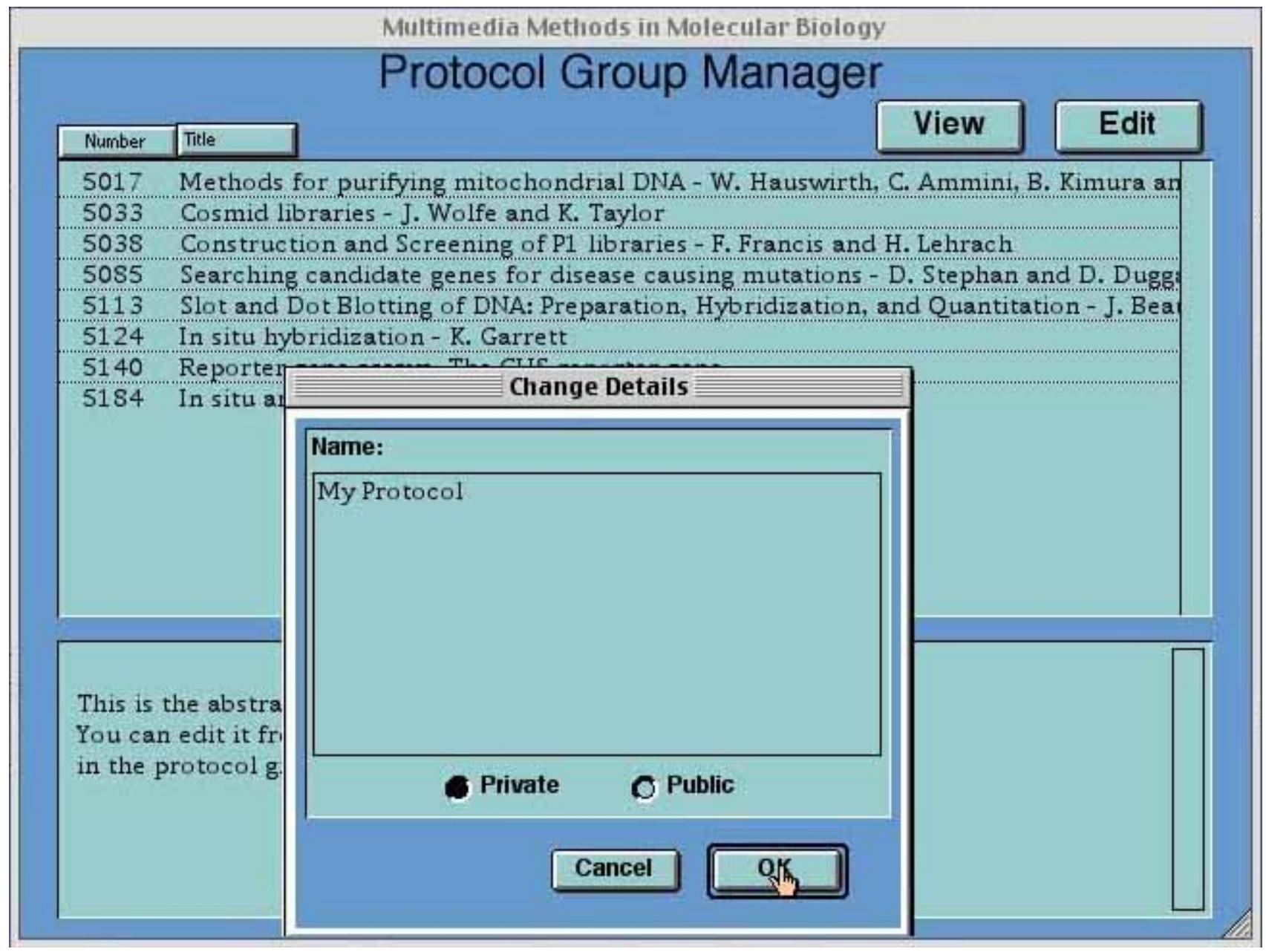

Fig.3b.: Como pode ser visto, este protocolo não deve ser acessado por pessoas não-autorizadas. 


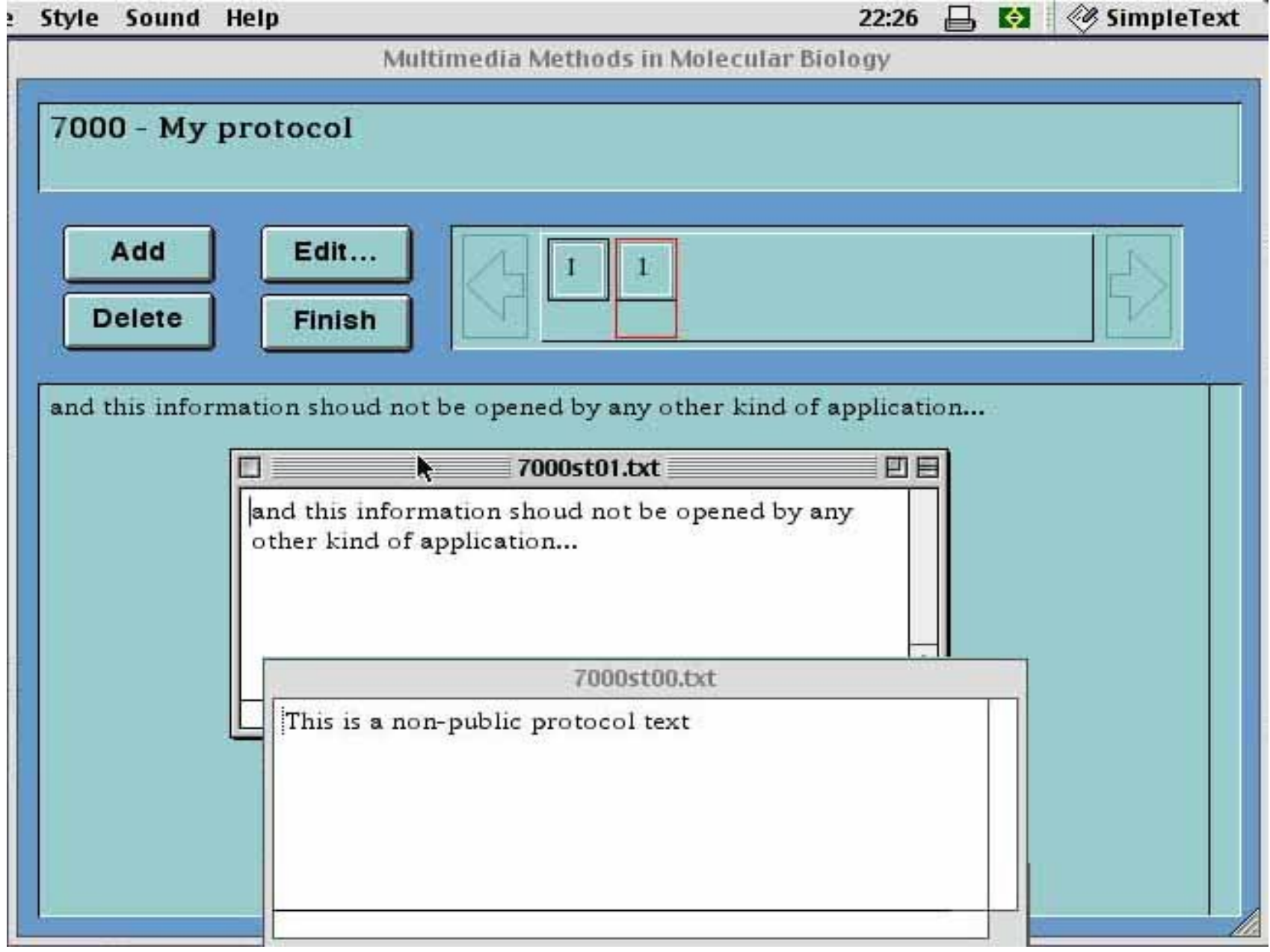

Fig.3c.: Portanto, isto não deveria acontecer... 3rd miss... Game Over!!!

Entretanto, é claro que se isso não for importante, deiso aqui o registro na última linha de que o pacote ainda se mostra bastante útil.

\section{Espaço: A Fronteira Final}

Existem muitas qualidades observadas neste pacote: acesso a páginas de hipertexto no endereço dos publicadores, uma grande quantidade de informação útil no dia-a-dia de um laboratório de biologia molecular experimental, adição de dados customizada (ou seja, editável), além da idéia da aplicação deste tipo de metodologia em si. Este é um material multimídia bastante interessante apesar da baixa qualidade gráfica e o problema do mecanismo de (in)segurança, se levado em consideração a proposta do pacote. É um bocado caro pelo que deve ser pago, mas ainda vale a pena dar uma olhada. Com tantas características antagônicas, ainda vale a pena adquirí-lo caso você tenha "um dinheirinho sobrando", ou se você é bastante generoso e gosta de incentivar este tipo de idéia. Mas ainda é bastante difícil adiquirir um pacote desses, vivendo num país como o Brasil, onde GBP1,00 equivale a BRR4,25 (não só isso, mas se isso equivale a $130 \%$ do valor dos ganhos mensais do autor desta revisão, em setembro de 2000). Realmente, esperamos observar futuras melhoras no pacote o mais breve possível. 